Journal of Advanced Research in Fluid Mechanics and Thermal Sciences

\title{
Characterisation Study of Taylor-Couette Flow in Fluid Mixture of Used Cooking Oil and Water
}

\author{
Adhi Kusumastuti ${ }^{1,}{ }^{*}$, Nur Qudus ${ }^{1}$, Widi Astuti ${ }^{1}$ \\ 1 Faculty of Engineering Universitas Negeri Semarang, Kampus UNNES Sekaran, Gunungpati, 50229 Semarang, Indonesia
}

\begin{tabular}{|c|c|}
\hline ARTICLE INFO & ABSTRACT \\
\hline $\begin{array}{l}\text { Article history: } \\
\text { Received } 7 \text { October } 2020 \\
\text { Received in revised form } 15 \text { February } 2021 \\
\text { Accepted } 20 \text { February } 2021 \\
\text { Available online } 3 \text { March } 2021 \\
\text { Keywords: } \\
\text { Taylor-Couette; Reynolds number; Taylor } \\
\text { number; shear stress; energy loss } \\
\text { distribution }\end{array}$ & $\begin{array}{l}\text { A study was done to investigate effect of volume ratio of water and used cooking oil } \\
\text { to the characteristic of Taylor-Couette flow in terms of shear stress and energy loss } \\
\text { distribution within Taylor-Couette column. The characterisation study was carried out } \\
\text { by applying water and waste cooking oil at volume ratio of } 1: 1,1: 3,1: 5 \text {, and } 1: 6 \text {. The } \\
\text { inner cylinder was rotated at } 300 \mathrm{rpm} \text { while the outer cylinder was kept static. It was } \\
\text { found that optimal volume ratio for wastewater treatment was } 1: 1 \text {, shown by the } \\
\text { phenomenon of Modulated Wavy Vortices flow regime. The highest Taylor number of } \\
1.01 \times 10^{7} \text { was also achieved in the volume ratio, while the shear stress was }-1.99 \text {. }\end{array}$ \\
\hline
\end{tabular}

\section{Introduction}

Continuous deformation occurs to fluid as it subjects to shear forces, even in very small shear forces [1]. Taylor-Couette flow occurs in the annular gap between two coaxial rotating cylinders which have different diameter. Experiments of Andereck et al., [2] was able to visualise fluid flow between two rotating concentric cylinders. A study of Min and Lueptow [3] applied porous cylinder as rotating inner cylinder, it was therefore, a part of circular and axial flows, a radial flow was also formed.

Saadevandi and Zakin [4] examined emulsion of silicone in water. Emulsion of silicone-water was produced in a homogeniser at variation of homogeniser rotation and variation of volume of silicone-water. It was revealed that those variables affected emulsion stability as well as shear stress.

Another study of Taylor-Couette flow was done by Ahmad et al., [5] through heavy metal removal. Emulsion liquid membrane system was applied for waste water treatment. The system utilised Taylor-Couette flow in a Taylor-Couette column. The device operated by applying the principle of Taylor-Couette flow. Emulsion instability, being the major problem of emulsion liquid membrane system, could be minimised by maintaining high extraction performance. In the

\footnotetext{
* Corresponding author.

E-mail address: adhi_kusumastuti@mail.unnes.ac.id
}

https://doi.org/10.37934/arfmts.80.2.106114 
extraction process, fluids viscosity of emulsion highly determines efficiency of wastewater treatment. Characterisation is unavoidable to determine flow type, shear stress, and energy loss distribution.

Ghannam [6] studied stability of water in crude oil emulsion. Emulsion stability was investigated under parameters of water concentration (10-50\%), surfactant concentration $(0.1-1 \%)$, mixing speed $(500-2,000 \mathrm{rpm})$, salt concentration (0-5\%), polymer concentration $(0-1,000 \mathrm{ppm})$, and temperature $\left(13-40^{\circ} \mathrm{C}\right)$. The research found that emulsion stability could be enhanced by surfactant as emulsifier. The increase of water concentration gradually decreased emulsion stability. Highly stable emulsion was provided by the addition of $\mathrm{NaCL} 5 \%$, while higher temperature decreased emulsion stability. It was shown that impeller type strongly affected emulsion stability, in which the most stable emulsion was generated by s-curved blade impeller.

Ariffin et al., [7] investigated rheological behaviour of crude oil emulsion. The study examined the variations of viscometry study as a function of shear rate, temperature and volume water fraction. It was exposed that the viscosity of water in oil emulsion was greatly affected by temperature, shear rate and volume ratio of water and oil. Consideration on the comprehensive factors is of important to minimise cost.

Characterisation study of water-in-oil emulsions in terms of rheological behaviour, stability and the amount of emulsions formed was done by Wong et al., [8]. Water-in-oil emulsion characterisations were investigated under the influence of water cuts in the range of 0 to $40 \%$, Reynolds number which covers laminar $(1100<\operatorname{Re}<1800)$ to turbulent $(2400<\operatorname{Re}<2800)$ flow regime and pipeline constrictions types. The study showed that for emulsion of below shear rates of $200 \mathrm{~s}^{-1}$ and $350 \mathrm{~s}^{-1}$ for $5-30 \%$ WC and $35-90 \%$ WC, respectively, emulsions exhibited shearthinning behaviour, while beyond the respected shear rates, emulsions turned to be Newtonian fluid. Emulsion composition of $40 \%$ WC triggered phase inversion from W/O emulsions to O/W emulsions. Stability study found that emulsion stability was enhanced by the increase of water cuts. Furthermore, higher Reynolds number generated more stable emulsion. In term of emulsion amount, it was revealed that it was governed by Reynolds number and water cuts, in which higher Reynolds number as well as water cuts leading to the increase of emulsion amount.

An examination of flow behaviour through square mitre bend with the effect of the particles as well as relationship of flow pattern to flow velocity for different types of particles was conducted [9]. Applying water as flow medium, research was performed on $90^{\circ}$ square mitre bend.

Study on the impact of flow regimes types of vertical pipes to the fluid flow measurements was carried out [10]. An OLGA simulation model was applied for simulation of actual well flow performance fluid flow measurements. Experiment was done in the vertical upward multiphase flow using well and reservoir properties. It was revealed that flow patterns were highly affected by liquid velocities, gas velocities, and water fraction. The study successfully generated three flow patterns, i.e. bubble, slug, and annular flow. It was also found that flow patterns were determined by the water cut.

Investigation on the effects of rotation and axial flow to the flow pattern in an annulus was performed [11]. In the system, the inner cylinder rotated while the outer cylinder fixed. System with radius ratio $(\eta)$ and aspect ratio $(\Gamma)$ of $=0.716$ and 40 , respectively, generated flow patterns of Laminar-Couette, Couette-Poiseuille, Spiral-Vortex, Wavy Vortex, and Turbulent-Taylor-Vortex. There was a tendency of turbulent axial vortex wavelength decrease by the increase of rotation speed to certain level. The propagation velocity of turbulent vortex, which was smaller than the average velocity of fluid flow, decreased at higher rotation.

Boogar et al., [12] investigated the effect of viscosity, surface tension, and flow rate on the flow regime of liquid-liquid two-phase. The used aqueous and organic working fluids were water and 
gasoil, respectively. Fluids viscosity was increased by the addition of xanthan gum, while fluids interfacial tension was decreased by the addition of Triton X-100 (TX-100) and Sodium Dodecyl Sulphate (SDS). It was demonstrated that despite the increase of viscosity and flow rate resulted in the increase of interfacial area, the flow regime of slug was remained unchanged.

Another study of the effects of liquid viscosity on the flow patterns was done by Furukawa and Fukano [13]. In the study, they employed three different liquids, i.e. water, 53 wt. \% gylcerol solution, and 72 wt. \% glycerol solutions. It was concluded that liquid viscosity strongly determined the flow pattern transitions.

A flow pattern study in a Taylor-Couette column was carried out by Kusumastuti et al., [14]. Fluid viscosity, estimated to govern the flow pattern, was studied by varying volume ratio of oil to water. TCC characterisation was done in terms of flow regimes, shear stress, and energy loss distribution. Flow regime of Turbulence Taylor Vortices (TTV) was found in all variation of volume ratio of oil to water.

Emulsion viscosity determines the effectivity of wastewater treatment during extraction process. It is therefore, a study on the investigation of the effects of volume ratio of water to usedcooking oil as well as rotation speed of inner and outer cylinders thus increasing the efficiency of wastewater treatment was carried out. A Taylor-Couette column was employed by applying counter current flow of inner and outer cylinders with different diameters. The rotation generated various flow patterns with respect to cylinder velocity and fluid viscosity.

\section{Method}

Experiments were done to explore the application of Taylor-Couette column to characterise water - used cooking oil. In the research, effects of volume ratio of water to used cooking oil as well as rotation speeds of outer and inner cylinders to the pattern flow were examined. The inner cylinder rotated at $300 \mathrm{rpm}$ while outer cylinder rotated at $0 \mathrm{rpm}$. Taylor-Couette flow pattern was obtained through calculation and image processing. Outer cylinder and inner cylinder of $40 \mathrm{~mm}$ and $24 \mathrm{~mm}$ in diameter, respectively, were employed in this research.

Kinematic viscosity and density of water and used cooking oil were determined, followed by the determination of dynamic viscosity. Furthermore, fluid flow in the Taylor-Couette column was characterised in various volume ratio of water to used cooking oil as well as rotation speeds of inner and outer cylinders. Schematic diagram of Taylor-Couette column is shown in Figure 1.

Water and used cooking oil were utilised based on the variation of volume ratio, i.e. 1:1, 1:3, 1:5, 1:6. The feed phase was then flowed to Taylor-Couette column through feeder tank. The rotation speeds of inner and outer cylinder were $300 \mathrm{rpm}$ and $0 \mathrm{rpm}$, respectively.

\section{Results and Discussion}

The measurement of kinematic viscosity and density was done at $40^{\circ} \mathrm{C}$. The results are given in Table 1. Table 1 revealed that kinematic viscosity of used cooking oil was higher than that of water, while density of used cooking oil was lower than that of water. 


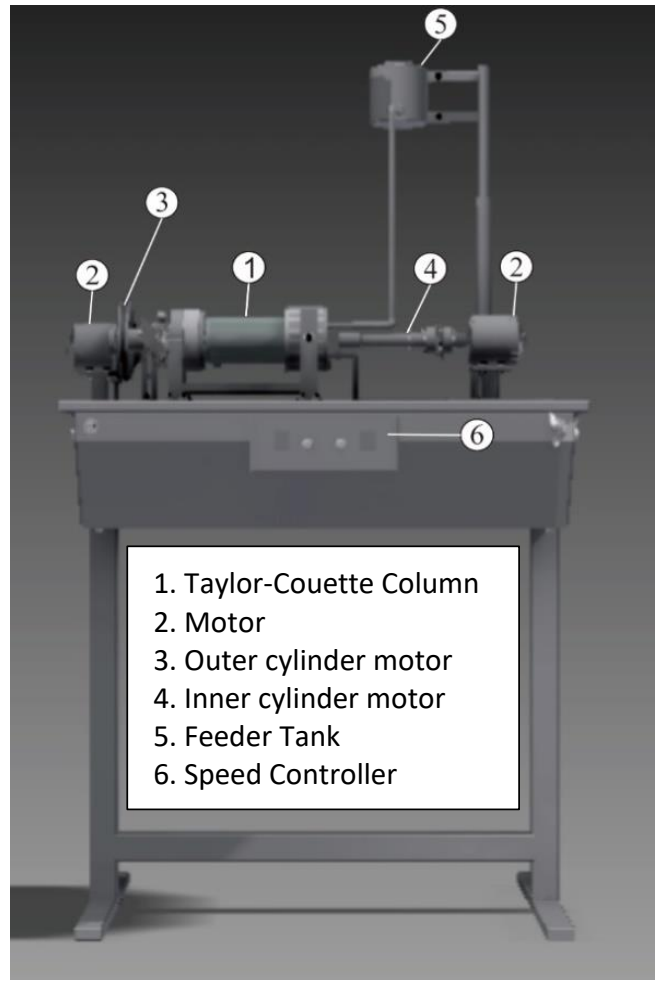

Fig. 1. Taylor-Couette Column

Table 1

Kinematic viscosity and density of water and used cooking oil

\begin{tabular}{lll}
\hline Material & Kinematic Viscosity $\left(\mathrm{m}^{2} \mathrm{~s}^{-1}\right)$ & Density $\left(\mathrm{kgm}^{-3}\right)$ \\
\hline Water & $7.174 \times 10^{-7}$ & 990.8 \\
Used Cooking Oil & $4.38115 \times 10^{-5}$ & 891.15 \\
\hline
\end{tabular}

\subsection{Determination of Kinematic Viscosity and Density of Fluid Mixture}

The determination of kinematic viscosity of fluids mixture was carried out using the following equation.

$\left(v_{\text {mixture }}\right)^{1 / 3}=x_{\text {water }} \cdot\left(v_{\text {water }}\right)^{1 / 3}+x_{\text {used cooking oil }} \cdot\left(v_{\text {used cooking oil }}\right)^{1 / 3}$

While the density of fluids mixture was determined as follow

$\rho_{\text {mixture }}=x_{\text {water }} \rho_{\text {water }}+x_{\text {used cooking oil }} \rho_{\text {used cooking oil }}$

The obtained kinematic viscosity and density of fluids mixture were then used to calculate the dynamic viscosity of fluids mixture as follow

$v=\frac{\mu}{\rho}$

which, $\quad v \quad=$ kinematic viscosity $\left(\mathrm{m}^{2} / \mathrm{s}\right)$,

$\rho \quad=\operatorname{density}\left(\mathrm{kg} / \mathrm{m}^{3}\right)$,

$\mu \quad=$ dynamic viscosity $\left(\mathrm{Ns} / \mathrm{m}^{2}\right)$. 
Table 2 describes the characteristics fluids mixture in terms of kinematic viscosity, dynamic viscosity, and density.

Table 2

Results of fluids mixture viscosity and density

\begin{tabular}{llll}
\hline Mixture Ratio & $\begin{array}{l}\text { Kinematic Viscosity } \\
\left(\mathrm{m}^{2} / \mathrm{s}\right) \times 10^{-5}\end{array}$ & $\begin{array}{l}\text { Density } \\
\left(\mathrm{kg} / \mathrm{m}^{3}\right)\end{array}$ & $\begin{array}{l}\text { Dynamic Viscosity } \\
\left(\mathrm{Ns} / \mathrm{m}^{2}\right) \times 10^{-2}\end{array}$ \\
\hline Ratio of 1:1 & 1.07975 & 940.975 & 1.02 \\
Ratio of $1: 3$ & 2.35848 & 916.063 & 2.16 \\
Ratio of 1:5 & 2.91662 & 908.091 & 2.65 \\
Ratio of 1:6 & 3.1467 & 905.101 & 2.85 \\
\hline
\end{tabular}

The highest kinematic viscosity was reached by system with volume ratio of $1: 6$, in which more used cooking oils is available thus generating thicker fluids mixture. The highest density was obtained by system with volume ratio of 1:1.

\subsection{Determination of Reynolds Number of Inner and Outer Cylinders}

Reynolds numbers were calculated to determine the flow pattern by using Eq. (4). The flow regimes based on Reynolds number of the inner and outer cylinder rotation are illustrated in Figure 2.

$R e_{i}=\frac{R_{i} \omega_{i} d}{v}$ and $R e_{o}=\frac{R_{o} \omega_{o} d}{v}$

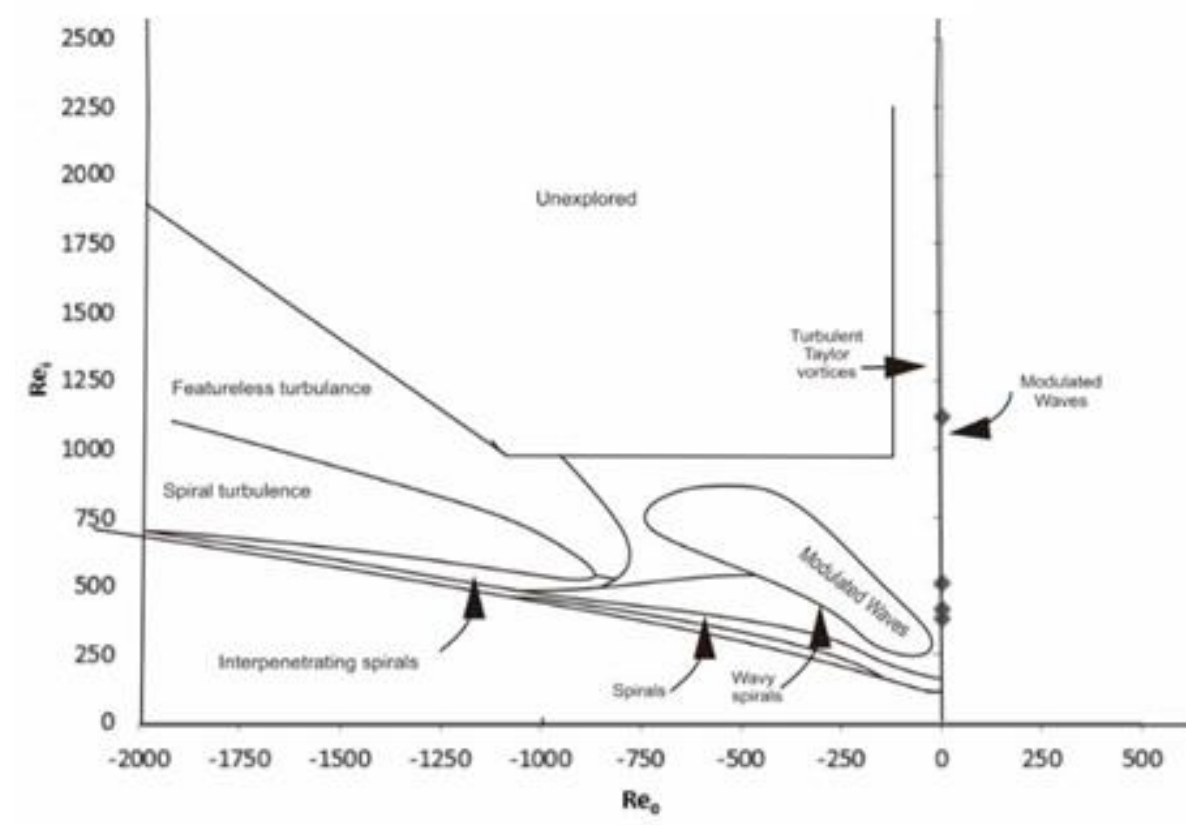

Fig. 2. Flow regime

Two types of Taylor Couette flow patterns were generated, i.e. Modulated Wavy Vortices and Wavy Vortex Flow. 


\subsection{Image Processing Analysis}

It was found that volume ratio of fluids mixture as well as rotation speeds of inner and outer cylinders determined the flow pattern. Systems with the same volume ratio generated different flow patterns due to the different speed of inner and outer cylinders.

Wavy vortex flow, generated by system with volume ratio of 1:3, 1:5, and 1:6 at rotation speed of inner and outer cylinders of $300 \mathrm{rpm}$ and $0 \mathrm{rpm}$, respectively, are described in Figure 3.

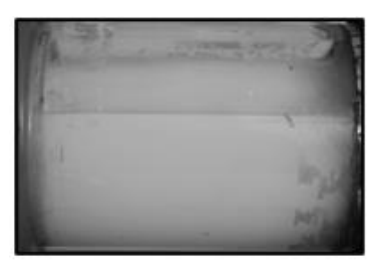

\section{$1: 3$}
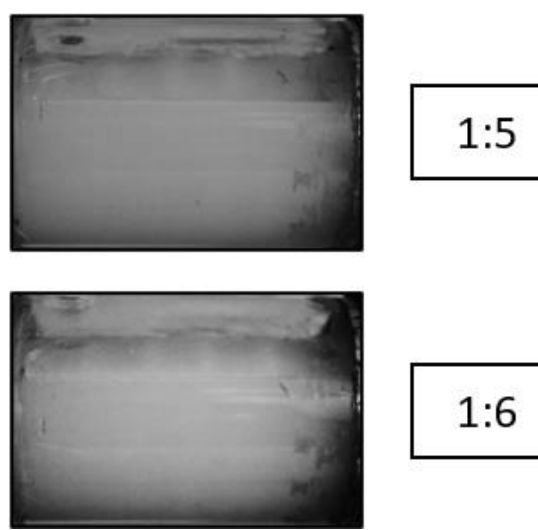

\section{$1: 6$}

Fig. 3. Wavy vortex flow

Volume ratio of $1: 1$ and rotation speed of inner cylinder of 300 rpm resulted in Modulated Wavy Vortices as shown in Figure 4.

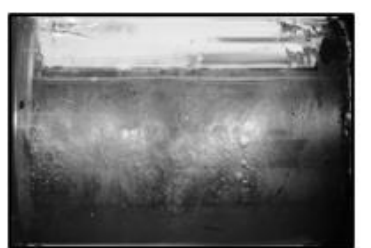

\section{$1: 1$}

Fig. 4. Modulated Wavy Vortices

\subsection{Determination of Taylor Number}

Taylor-Couette flow was characterised using Taylor number. The calculation of Taylor number was given below [15].

$T a=\frac{1}{4} \sigma\left(R_{o}-R_{i}\right)^{2}\left(R_{o}+R_{i}\right)^{2}\left(\omega_{i}-\omega_{o}\right)^{2} v^{-2}$

In which

$\sigma=\{((1+\eta) / 2) \sqrt{\eta}\}^{4}$ 
Figure 5 shows that Taylor number increased with the increase of volume ratio. Higher rotation speed of inner cylinder $\left(\omega_{i}\right)$, provided higher Taylor number. System with lower water composition resulted in lower Taylor number. The highest Taylor number of $1.01 \times 10^{7}$ was generated by system with volume ratio of 1:1, while system with volume ratio of 1:6 resulted in the highest Taylor number of $1.19 \times 10^{6}$.

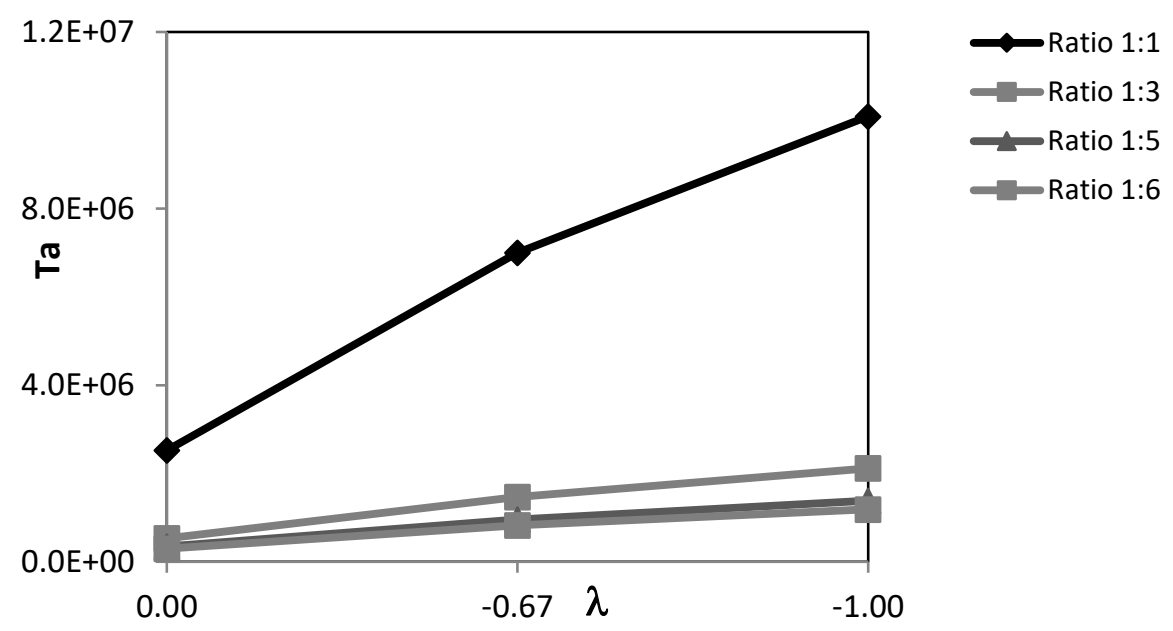

Fig. 5. Profile of Ta to $\lambda$ at $\omega_{i}=31.4 \mathrm{rad} / \mathrm{s}$

\subsection{Determination of Shear Stress}

To determine shear stress of fluids flow, the following equation was applied [15].

$\tau=-2 \mu \frac{B}{R_{i}^{2}}$

Figure 6 describes the profile of shear stress as a function of cylinder rotation speed. Higher rotation speed of inner cylinder $\left(\omega_{i}\right)$ provided higher shear stress. Volume ratio of 1:1 resulted in the highest shear stress of -1.99 , while system with volume ratio of 1:6 generated the highest shear stress of -5.59 .

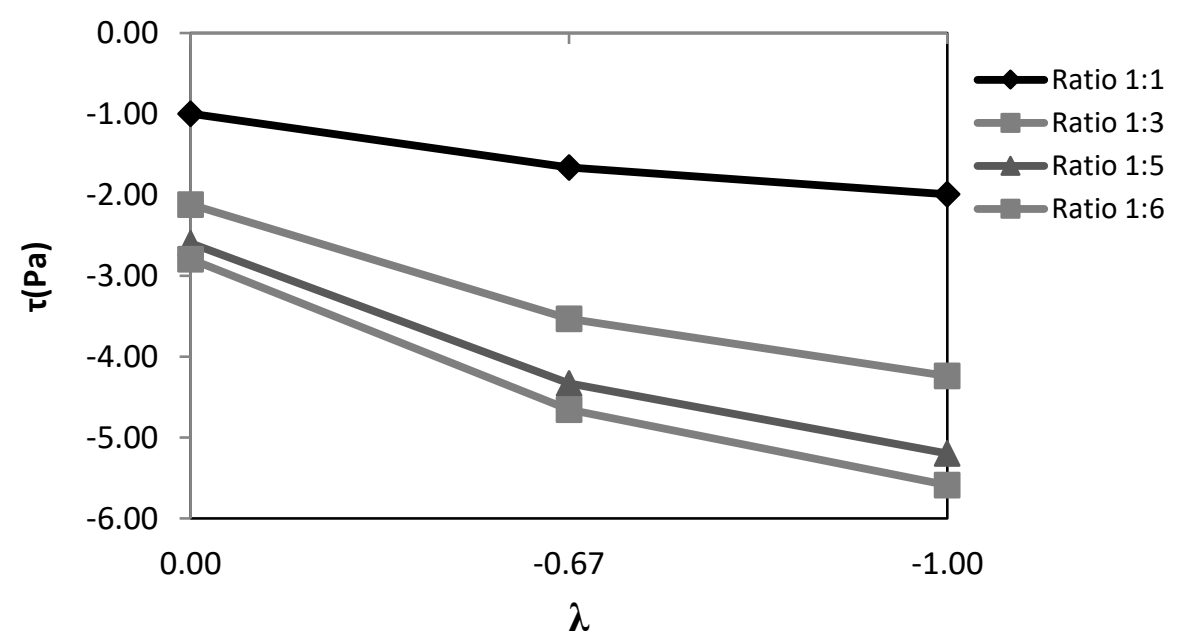

Fig. 6. Shear Stress at $\omega_{\mathrm{i}}=31.4 \mathrm{rad} / \mathrm{s}$ 


\subsection{Determination of Energy Loss Distribution}

Equation of Dou et al., [16] was employed to determine energy loss distribution which respects to the amount of energy loss on the fluids flow. The equation is as follow

$\frac{d H}{d s}=4 \mu \frac{\omega_{i} R_{i}}{d^{2}} \frac{R_{i}^{4}}{r^{4}} \frac{(1-\eta)^{2}}{\eta^{2}} \frac{(1-\lambda)^{2}}{\left(1-\eta^{2}\right)^{2}}\left[\frac{\eta^{2}-\lambda}{\eta^{2}-1} \frac{r}{R_{i}}+\frac{R_{i}}{r} \frac{1-\lambda}{1-\eta^{2}}\right]^{-1}$

$r$ refers to profile of $R_{i}$ to $R_{o}$, available in 15 points in the interval of $0.025-0.039$.

Profile of energy loss distribution is described in Figure 7 . In the figure, $\lambda$ refers to the ratio of rotation speed of outer cylinder to inner cylinder. The $\lambda_{1}$ and $\lambda_{15}$ were 0 and -0.43 , respectively. It was revealed that at outer cylinder rotation speed, $\omega_{o}=0$, the energy loss distribution, $\left(r-R_{i}\right) / d=1$. System with outer cylinder rotation speed, $\omega_{o}>0$, resulted in infinity points on certain cylinder gaps. The experiment showed that volume ratio of fluids mixture affected the energy loss distribution. In the same position, energy loss distribution of the system with volume ratio of 1:3 was higher than that of volume ratio of 1:1. Higher dynamic viscosity provided higher energy loss distribution.

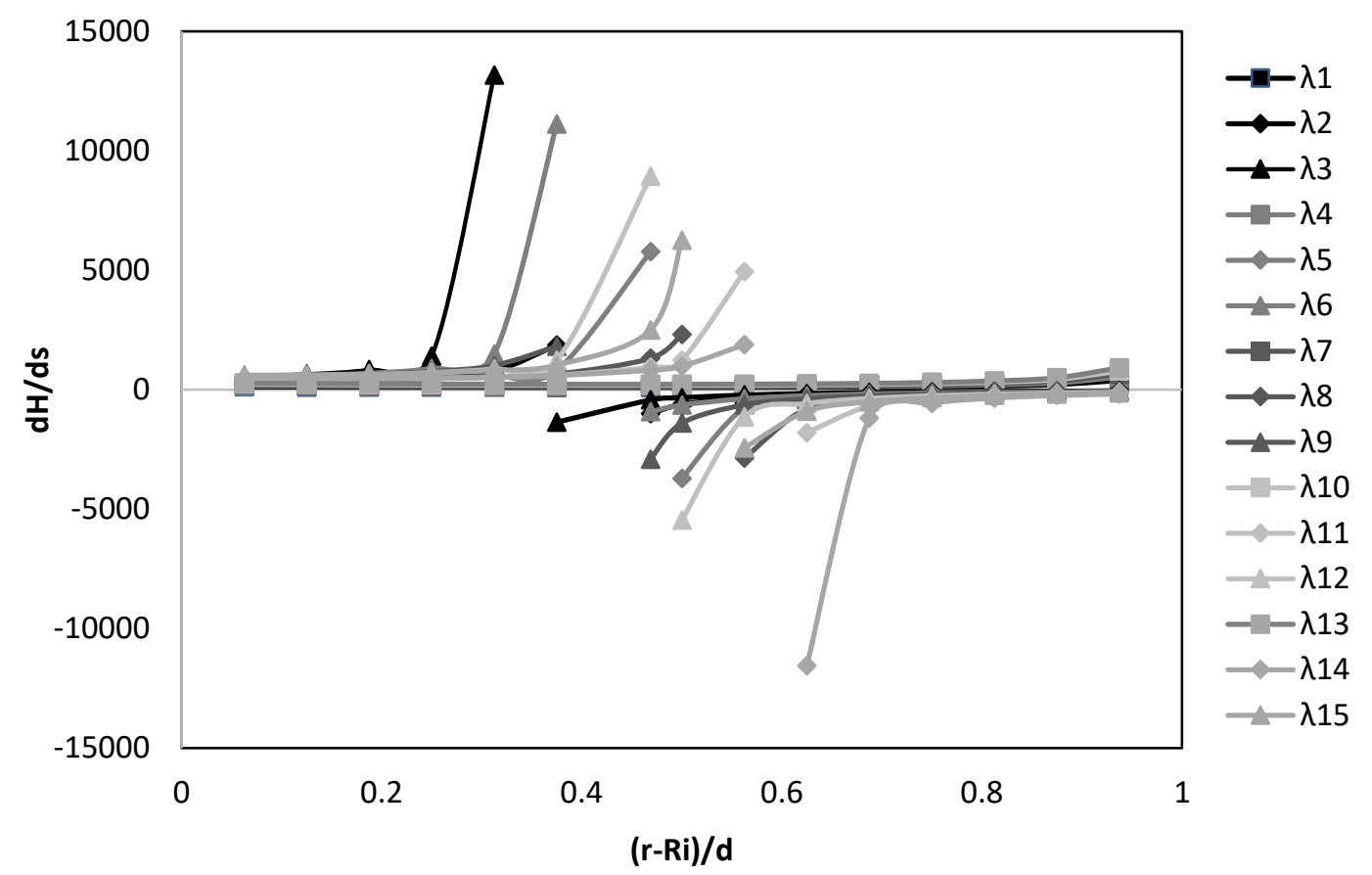

Fig. 7. Profile of energy loss distribution at volume ratio of 1:1

\section{Conclusion}

Characterisation study of used fluids mixture in a Taylor-Couette column has been done. It was seen that different volume ratio of fluids mixture significantly determined the generated flow regime. System with volume ratio of $1: 1$ provided high Reynolds number. This is due to the low kinematic viscosity of the fluids mixture thus resulted in more turbulent flow. Rotation speed of inner and outer cylinders is another affecting factor for flow regime, higher rotation speed leads to higher turbulence level.

Dynamic viscosity of the fluid's mixture was also important in determining shear stress. System with higher dynamic viscosity provided higher shear stress. Moreover, shear stress was also 
governed by rotation speeds of inner and outer cylinders. Higher energy loss distribution was obtained at higher dynamic viscosity. System at stationary outer cylinder $\omega_{o}=0$ achieved $\left(r-R_{\mathrm{i}}\right) / \mathrm{d}$ of about 1.

\section{Acknowledgement}

Fundamental research grant funded by the Ministry of Education and Culture of the Republic of Indonesia is gratefully acknowledged.

\section{References}

[1] Kumar, K. L. Engineering Fluid Mechanics (Single Color Edition). S. Chand Publishing, 2016.

[2] Andereck, C. David, S. S. Liu, and Harry L. Swinney. "Flow regimes in a circular Couette system with independently rotating cylinders." Journal of Fluid Mechanics 164, no. $3 \quad$ (1986): $155-183$. https://doi.org/10.1017/S0022112086002513

[3] Min, K., and R. M. Lueptow. "Circular Couette flow with pressure-driven axial flow and a porous inner cylinder." Experiments in Fluids 17, no. 3 (1994): 190-197. https://doi.org/10.1007/BF00190916

[4] Saadevandi, Bram A., and Jacques L. Zakin. "A study of silicone oil-in-water emulsions." Chemical Engineering Communications 156, no. 1 (1997): 227-246. https://doi.org/10.1080/00986449708936678

[5] Ahmad, A. L., Adhi Kusumastuti, MMH Shah Buddin, C. J. C. Derek, and B. S. Ooi. "Emulsion liquid membrane based on a new flow pattern in a counter rotating Taylor-Couette column for cadmium extraction." Separation and Purification Technology 127 (2014): 46-52. https://doi.org/10.1016/i.seppur.2014.02.029

[6] Ghannam, Mamdouh T. "Water-in-crude oil emulsion stability investigation." Petroleum Science and Technology 23, no. 5-6 (2005): 649-667. https://doi.org/10.1081/LFT-200033001

[7] Ariffin, Tajnor Suriya Taju, Effah Yahya, and Hazlina Husin. "The rheology of light crude oil and water-in-oilemulsion." Procedia Engineering 148 (2016): 1149-1155. https://doi.org/10.1016/j.proeng.2016.06.614

[8] Wong, Siew Fan, Sharul Sham Dol, Siaw Khur Wee, and Han Bing Chua. "Miri light crude water-in-oil emulsions characterization-Rheological behaviour, stability and amount of emulsions formed." Journal of Petroleum Science and Engineering 165 (2018): 58-66. https://doi.org/10.1016/j.petrol.2018.02.013

[9] Ismail, Ainaa Maya Munira, Fazila Mohd Nawawi, and Jamaludin Md Sheriff. "Flow Pattern of Particle Contamination in Fluid Flow Through Mitre Bend." Journal of Advanced Research in Fluid Mechanics and Thermal Sciences 45, no. 1 (2018): 128-140.

[10] Ganat, Tarek, and Meftah Hrairi. "Effect of Flow Patterns on Two-Phase Flow Rate in Vertical Pipes." Journal of Advanced Research in Fluid Mechanics and Thermal Sciences 55, no. 2 (2019): 150-160.

[11] Prajitno, Sutrisno, Indarto, and Purnomo. "Pola Aliran Couette-Taylor dengan Aliran Aksial." Thermofluid Seminar Nasional Pameran Teknologi Gas (2011): 123-127.

[12] Boogar, Rahman Sadeghi, Reza Gheshlaghi, and Mahmood Akhavan Mahdavi. "The effects of viscosity, surface tension, and flow rate on gasoil-water flow pattern in microchannels." Korean Journal of Chemical Engineering 30, no. 1 (2013): 45-49. https://doi.org/10.1007/s11814-012-0119-8

[13] Furukawa, T., and T. Fukano. "Effects of liquid viscosity on flow patterns in vertical upward gas-liquid two-phase flow." International Journal of Multiphase Flow 27, no. 6 (2001): 1109-1126. https://doi.org/10.1016/S03019322(00)00066-5

[14] Kusumastuti, Adhi, Gunawan Muhammad Najibulloh, Nur Qudus, and Samsudin Anis. "Flow regime analysis of Taylor-Couette column for emulsion liquid membrane applications." In AIP Conference Proceedings, vol. 2124, no. 1, p. 020047. AIP Publishing LLC, 2019. https://doi.org/10.1063/1.5117107

[15] van Gils, Dennis Paulus Maria, Sander Gerard Huisman, S. Grossmann, Chao Sun, and Detlef Lohse. "Optimal Taylor-Couette turbulence." Journal of Fluid Mechanics $706 \quad$ (2012): $118-149$. https://doi.org/10.1017/ifm.2012.236

[16] Dou, Hua-Shu, Boo Cheong Khoo, and Khoon Seng Yeo. "Energy loss distribution in the plane Couette flow and the Taylor-Couette flow between concentric rotating cylinders." International Journal of Thermal Sciences 46, no. 3 (2007): 262-275. https://doi.org/10.1016/j.ijthermalsci.2006.05.003 